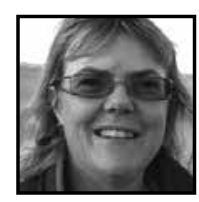

\title{
Unlearning to Be the Teacher: Findings From an Action Research Study
}

\author{
Gail Casey, Deakin University
}

\section{ABSTRACT}

As the practitioner-researcher, the author integrated social and participatory media into her classes. Action research was used to explore how such media might enhance learning. The study found that the unique qualities of new media could be used to develop an active environment; students learned a lot from each other. Many complexities and tensions emerged and a shift in the teacher-to-student relationship occurred resulting in the need for the author to unlearn many past teaching practices.

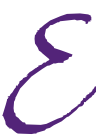

ach morning I still check my Facebook account for interaction or communication from my two adult children and I often upload pictures and stories of interest for my family and friends. I remember when my daughter posted a request for guidance in constructing a garden bed; a number of her online friends soon recommended construction approaches along with supportive websites. The speed at which she received this help, and the depth of thinking and critical analysis that occurred online, continued to play over in my mind and left me with questions of how social interaction and the value of online friends could be used to support learning and curriculum in more structured educational programs.

Back in 2007, I was teaching English as a Second Language in South Korea when, as part of my studies for a Master of Education, I began the journey of a practitioner-researcher using action research. In a practical sense I began to trial the use of blog as a form of social media between Australian and Korean high school students. As an educator, I found action research to be very empowering and continued to use it as a mechanism to explore the integration of social and participatory media within my face-to-face 
classes. My 15 years of experience in teaching and leading with technology includes both large multi-campus schools as well as regional and remote schools. This article discusses part of the action research study and details some of the significant teacher complexities, tensions, and challenges that were encountered. As the teacher and the action researcher, I collected data over an 18-month period during 2010 and 2011 in an Australian public secondary school where I had taught for five years. I was teaching Mathematics and Information Technology (IT) and the students were 13-16 years of age. The school was classified as mid socio-economic status and was set in a regional city with a population of approximately 140,000 . It was a co-educational school with about 900 students. In discussing the pedagogical and curricular changes that occurred throughout the study, this article highlights the ways in which the unique qualities of social and participatory media were used in my teaching and learning programs.

\section{Background}

This action research was influenced by Nuthall's (2007) argument that students learn a lot from their peers, and teachers cannot be effective unless they take these peer relationships into account. It also considered the use of mobile devices and digital media to provide new avenues for peer-to-peer communication. Modes of learning continue to evolve and, as Davidson and Goldberg (2009) suggest, our sources of information, the ways we exchange and interact with it, and how information informs and shapes our lives, have also changed. As part of Davidson and Goldberg's (2009) research on digital media and learning for the MacArthur Foundation, they argue that the most important characteristic of the Internet is its capacity to allow for a worldwide community (and its myriad subsets) to exchange ideas and to learn from one another in ways not previously available. Their research examines potential new models of digital learning and it views participatory learning as a key term in thinking about emergent shifts. They explain that participatory learning includes the many ways that learners (of any age) use new technologies to participate in virtual communities where they share ideas, comment on one another's projects, and plan, design, implement, advance, or simply discuss their practices, goals, and ideas together. As practitioner-researcher, I used Davidson and Goldberg's (2009) concepts of participatory learning with the aim of building a shared online student-centred environment where students could interact across all of my classes, have opportunities to learn from their peers, and access resources anytime and anywhere. 
A number of theorists and researchers have guided this study, including Zhang (2012), who explains that teaching and learning encourages recursion and the view of recursion instruction holds that the teacher's authority, and the relationship between the teacher and students, is dynamic. For educators, these concepts of authority, at times, can merge and they may be left examining concepts of "who is teaching whom?" These ideas blend well with Hamilton's (1990) learning by "seeking out" knowledge, Dunbar's (1996) complexity of the social whirl, and Doll's (1993) self-organization of curriculum. It is important to also consider the question of what counts as knowledge. Ludvigsen (2012) argues that one must consider how and what kind of knowledge is perceived as valuable, or, alternatively, what knowledge becomes invisible in schools. Ludvigsen (2012) explains that, "this challenge makes us sensitive to changes in how knowledge is negotiated and treated in institutional practice" (p. 41).

This study connects very well with McWilliam's (2008) concept of "unlearning." She argues that contemporary life demands, not only that we learn new forms of social engagement, but also that we unlearn habits that have been useful in the past but are no longer valuable. Her unlearning concepts come from a re-positioning of the teacher and they incorporate students as co-directors and co-editors of their social world. She proposes that the long-term notion of a good teacher should be challenged and that there should be:

(1) less time giving instructions and more time spent being a usefully ignorant co-worker in the thick of the action;

(2) less time spent being a custodial risk minimiser and more time spent being an experimenter and risk-taker;

(3) less time spent being a forensic classroom auditor and more time spent being a designer, editor and assembler, and

(4) less time spent being a counsellor and 'best buddy' and more time spent being a collaborative critic and authentic evaluator. (p. 265)

\section{Research Design, Data Collection, and Context}

Throughout this qualitative study I used Armstrong and Moore's (2004) action research framework involving cycles of planning, acting, observing, and reflecting while being supported by critical friends. Generally, one action research cycle was one class topic, but a number of class topics were taught simultaneously with different subjects and ages: hence, what was learned from one class cycle helped to inform other 
action research cycles in other classes. The study was broken down into three research questions and these were used to develop a social framework for learning.

Students: What scaffolding is needed to help students learn within the complexity of an online social environment?

Learning: How can this framework help meet the learning and curriculum needs for schooling?

Teachers: What new demands could this type of framework bring to teachers and what professional development is needed to support such change?

The study occurred during the first two stages of my school's "one laptop per student" implementation program. The research participants were students from the 13 classes that I taught over an 18-month period, and the research spanned three semester-length phases. Each class spanned one semester (approximately 20 weeks) and each class had an average of 25 students.

Phase A: Semester 2, 2010, seven classes

Phase B: Semester 1, 2011 five classes

Phase C: Semester 2, 2011 one class

Each semester, I created one social networking site, called a Ning (http://ning.com), to share among all of my classes; hence, students could interact with students from all of my mathematics and information technology classes. More details of each of the components within the Ning social network are provided in Casey (2013). For privacy reasons, students used pseudonyms and were asked, even in the face-to-face classroom, not to disclose their identities. Online groups were constructed for project work, but usually the subject name and/or year level was not identified online; this was done to encourage students across my classes to interact. Students also created their own informal groups based on their interests and expertise, providing opportunities to learn from each other, share their knowledge, and socialize.

Microsoft OneNote software was used to store all of the data collected, and templates were created for class planning and reflection notes within this software. OneNote was also used to take screen captures of students' online work during most classes and to embed a range of other digital data within the templates. Data collected included the teacher's planning documents; classroom reflections and field notes; screen captures of students' online activities and tasks; the teacher's weekly, mid-semester, and end-ofterm reflections, as well as critical friend and peer feedback. Each of the three research questions were broken down and allocated tags to help with analysis. Once the data 
was tagged in relation to the three research questions, a range of summary tables were created, allowing further analysis to be carried out on each curriculum topic within each class.

The three social networking sites, created over the 18-month data collection period, were not constructed for the purposes of showcasing students' near-perfect work to a wider audience. Rather, they presented much of the daily interaction that became part of the teaching and learning process; hence, they included many of the half-attempts and failures that coincided with students' learning. More details of how this approach supported concepts of knowledge building are discussed further in Casey (2011) and (Casey \& Evans, 2011).

Figure 1 shows the main social networking site used during one of the three data collection phases. This screen capture helps to identify the range of activities available to students. The left-hand side of the webpage provides the students with quick links to the teacher's projects. The central area of the screen capture reminds students of the need to respect others and the need to use pseudonyms and not to post identifiable content. Students enjoyed creating their online identities and using the sites listed to create their individual avatar. The main menu is shown at the top section of the figure and provided students with quick access to many of the social tools. Each member of the site had access to his or her own "My Page," which highlighted that member's profile and provided links to the member's many activities, groups, and uploaded or usergenerated content. It also contained an area where students could receive comments from their peers and the teacher. 


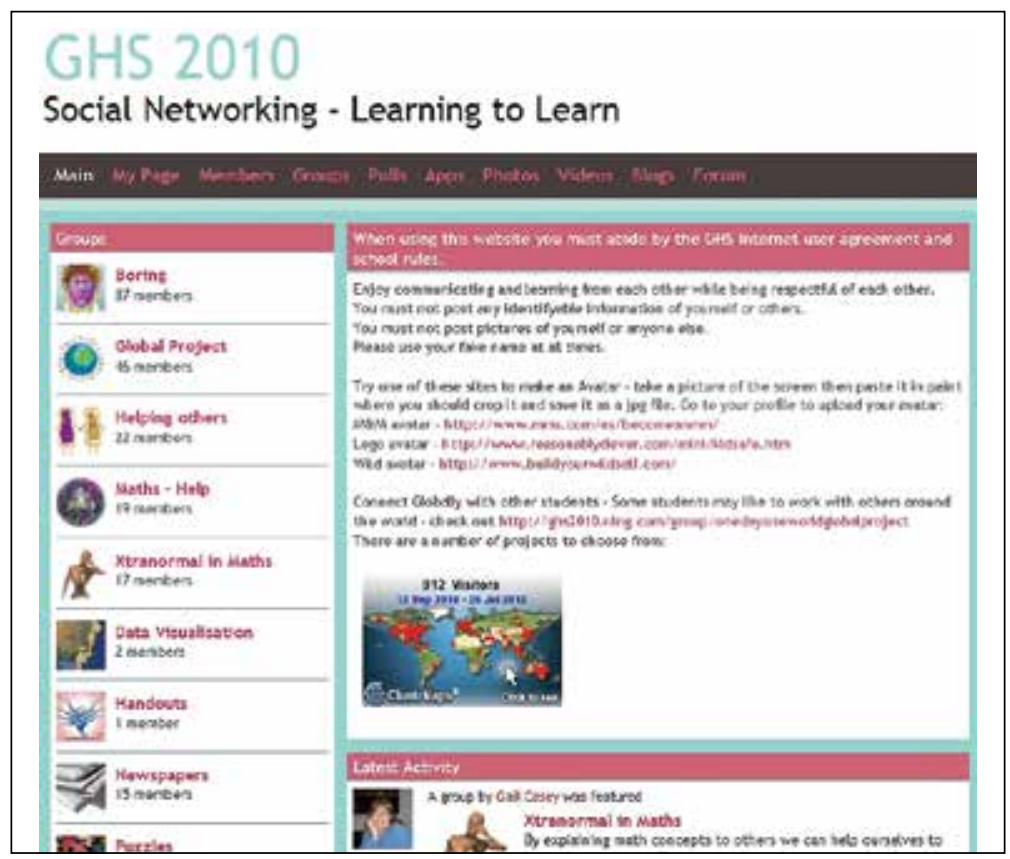

Fig. 1: The main page of the social media site used during Phase $A$

\section{Teacher Reflection and the Changing of Classroom Practices}

Many challenges were identified within the teacher reflection data and often these concerned my perception, at any point in time, of how best to use classroom and organizational time. I continued to consider how important is this and what is a good teacher or effective teaching? However, the teacher reflection data show that these perceptions changed over time, indicating that my teacher mind-set evolved over the 18 months. The following pages provide more insight into the teacher reflection data while detailing examples of classroom projects and student activity to highlight the changes in teacher practices including using students as resources.

\section{Change in Teacher Practices}

During the first phase of data collection, as expected, the data showed that it took time to establish projects online and to moderate the social classroom. Time was needed, in addition to my usual teacher work, not only to create class projects, but also 
to redesign them in order to take advantage of the interactive qualities of the social media. Initially, time was a significant problem, as was noted in the end of Phase A data where 77 interactive groups were created with more than 40 of these being studentinitiated (groups unrelated to class projects). I needed extra time (which could only come from my personal/private hours) to maintain the online site in conjunction with the usual, more traditional, teaching behaviours. The following teacher reflection was common during the first phase of data and captures the feelings of frustration with time factors.

There is never enough time to do everything. I continually want to create new things, online, for my students. I don't do some of the things I should do as a teacher and I should be doing some things better. With such time constraints I focus on those things that I enjoy most, which for me is creating new things and helping students learn from each other. I don't have time to fully prepare everything in detail so I add a few ideas and Internet links to the site and have my students experience things with me.

This reflection highlights teacher conflict between integrating social media into the classroom while trying to meet self and school expectations of the, somewhat, traditional instructor.

The teacher reflection data also showed that, due to time pressures, I was not able to monitor student progress in the same manner as previously, where I kept ongoing records of student progress and students' completed work. However, the classroom observations and field notes did provide adequate information regarding the standard of work and the students' approach to work. In other words, these allowed me to get a feel for how students were progressing. As the study continued, the action research cycles of improvement were used to approach assessment differently. By the end of the second phase, the data showed that implementing student self-assessment and peer-assessments, combined with classroom observations, were able to provide very detailed information. This had the advantage of including, more specifically, what students had done and why they had done so. It also included information such as the problems particular students encountered and the ways in which their peers had contributed. As the study continued, I modified my teaching and assessment practices and reduced the time spent correcting and monitoring student stages of work progress. By the middle of the second phase, the reflection data show that I became comfortable with this new approach to assessment, which resulted in less time needed to tediously record specific work as done or not done. It was notable that the parents, as well as the school administration, were very pleased with this type of data being used for 
assessment purposes. However, it is important to note that the teacher reflection data, throughout the process of achieving this successful assessment process, identifies a significant pedagogical struggle with my beliefs regarding my role as a good teacher.

Teacher reflection data also indicated that more time was spent with individual students and small groups. I was able to spend more time to better understand students' individual learning needs. Aspects of this could be seen through a student's Ning "My Page." This was a page that the social media site provided for every member and it became a type of ePortfolio for each student. It also provided, for any particular student, links/access to posts and user-created content as well as the student's online friends and the groups in which the student was involved. A student's My Page became an excellent resource to document specific work practices of a student at any point in time. It was notable that as students became more responsible for peer feedback and peer assessment, the teacher reflection data indicated that the teacher-to-student relationship was changing.

\section{Students as Resources}

As each research phase progressed, the curriculum was designed and scaffolded in ways that ensured that peer support and peer feedback would progressively increase. In daily classroom experiences, I continued to search for signs of a shift in students' attitudes to learning. In the reflection data, some of these were described as shifts from the "mundane to magical." Four examples are provided in the following pages to demonstrate this shift. The first is from a Year 9/10 class where students were searching the Internet in preparation for an exam. Students used Hendron's (2010) concept of "buckets" of information with the aim of developing "info-seeking" fluency skills. They did this through a process of sharing their search results by posting their content on blogs and recording the web address of their source materials. They used these "buckets" of information and those of their peers to "harvest" (Hendron, 2010) what each student felt was credible. This involved students publishing their own summary of their topic and exchanging peer feedback using the comment section of a blog. One of the teacher reflections in this project included:

While I was helping individual students, I could hear others, in a critical voice, accusing their peers of copying and pasting material from the Internet as their own work. Students were learning from each other, sharing knowledge and becoming critics while also being a supportive resource. 
Blogs were often used by students for posting their project ideas and content. Using a blog often enabled a visual representation of their thinking and work practices while providing a mechanism for direct and specific feedback from peers and/or myself, as the teacher. After posting a blog, students could find their blog listed on the main blog page. It became common class practice for a student to obtain a team of peer reviewers/critical friends by selecting the peers listed immediately above them and below them, on the main blog page, as well as one other of the student's choice. These peers would provide progressive feedback and, ultimately, assessment. The action research cycle was used to strengthen the scaffolding needed to support this peer-to-peer feedback and assessment. In turn, this built a strong student-centred framework that provided insight into the Student and Learning research questions and acknowledged a change in the student expectation of the teacher.

The second example considers a common theme within most classes where students were involved in creating some form of helpful resource for peers, either in their classroom or across the classes that I taught. In this particular example, mathematics students used web cameras to record their pencil-and-paper solutions while also recording a verbal explanation. This was a challenging task for students because it required them to demonstrate their depth of understanding within a particular topic. It also required students to consider how they learned to solve the mathematical problem and what was needed when considering how their peers might learn. Once students made and published these online, the consequent task then required critical thinking as students provided online peer-feedback. The reflection data show that the teacher-to-student conversations changed during this task and moved from questions of how to a deeper level involving questioning concepts of why within mathematics while paying particular attention to correct mathematical language.

The third project example provides a snapshot of one of the ways I tried to include student individual skills and knowledge, as well as flexibility, into the design of curriculum. The project involved students setting up their own groups and forums to share their knowledge and expertise in using a computer. (This occurred not long after students received their new individual laptop.) The purpose was to build a collective knowledge base where students could interact less formally with the aim to generate personal interest and share their "funds of knowledge" (González, Moll, \& Amanti, 2005, p. 47). The screen capture, shown in Figure 2, identifies four students with different avatars that have the pseudonyms, metalhead 1977, me-is-good, crazysis, and Sword of justice. Also shown are the four discussion forums they created to share their understanding of the different software types: Skype, Game maker, PowerPoint, and Picnic. The peer comments, as well as the teacher reflection data, showed that 
peers appreciated this sharing of expertise and, consequently, students were able to learn a lot from each other. This activity also enabled students to identify potential avenues of peer support for other project work.

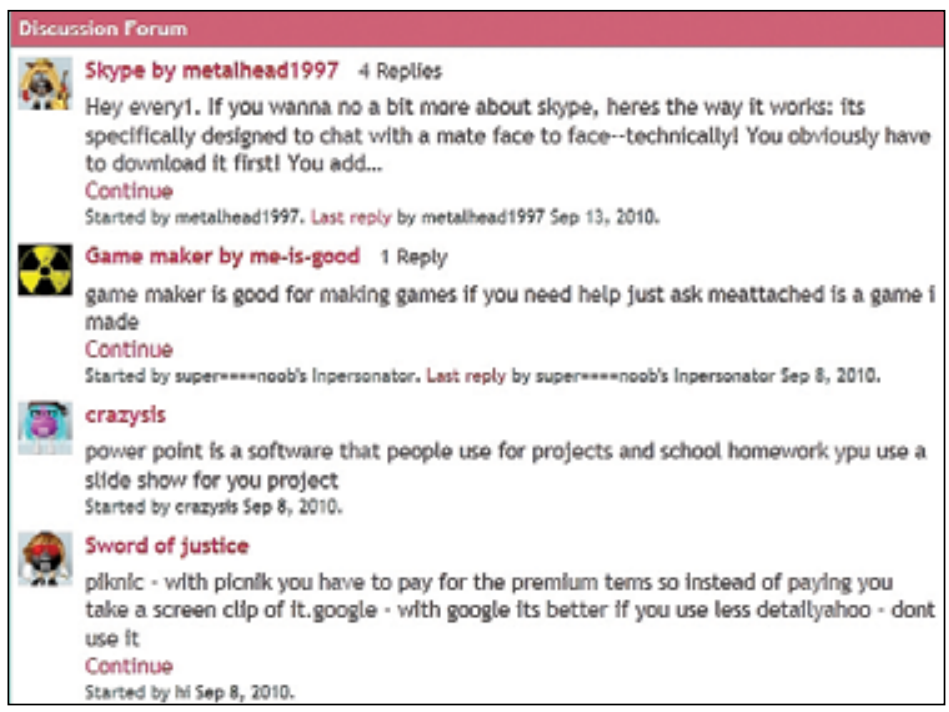

Fig. 2: Students were asked to create groups and forums to share knowledge and skills

In addition to the social media tools being used to design, create, and publish project work, students created informal groups and these allowed them to discuss such things as their interests in sport, hobbies, and music as well as how they were feeling. It could be considered that students were able to combine work and play. In these informal groups there was no expectation for students to learn, but they offered many teaching moments and the teacher reflection data show a range of examples where such discussions were integrated into the curriculum. When monitoring student informal groups, I often posted comments and questions and tried to role model appropriate interaction. Figure 3 shows some of the 45 groups created during Phase $C$ of the study. These included both formal groups such as "Math" and "Romania What do we know?" as well as informal groups such as "RIP Dan Wheldon" and "FUNNY PICTURES." 


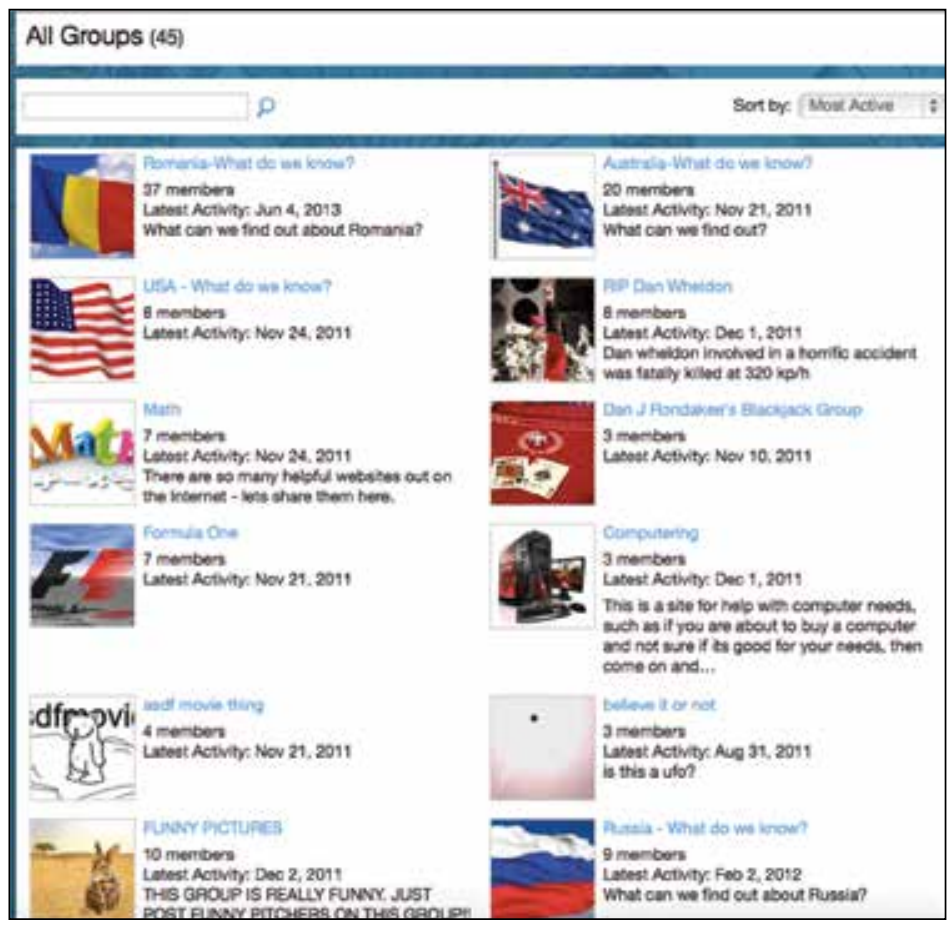

Fig. 3: Formal and informal groups were formed, 45 in total during Phase $C$

The fourth example involves one of the many student informal discussion groups where a particular discussion group posted humorous animations and pictures. The data show how I used this group to draw students' attention to the countries from where the animations originated as well as how the animations were created: concepts that held important curriculum value for Information Technology classes. It was found that encouraging students to create and engage in informal discussion groups held potential for teaching moments and provided students with social interaction that often supported curriculum content and learning practices. Figure 4 is a screen clip of a student's "My Page." The student used the pseudonym, Explosive Bean, and the My Page shows that Explosive Bean had received two gifts, posted eight blogs, and joined three groups. Figure 4 also shows a list of the "Latest Activity" for Explosive Bean where students with the pseudonyms, A Lemon and Jo have left comments for Explosive Bean and relate to a class project where students were creating games for their peers. Such comments provided students with authentic and timely feedback, which were generally appreciated and used for improvement before final assessment. 


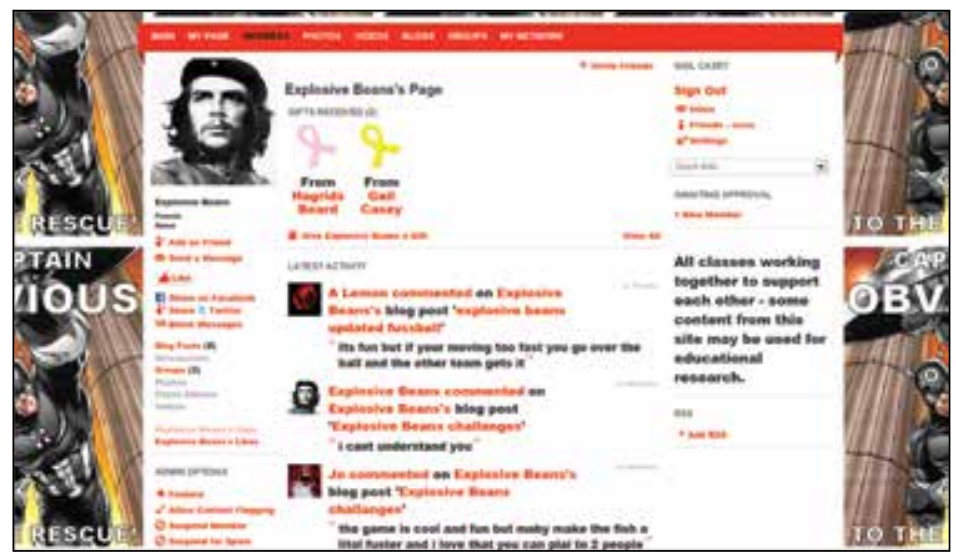

Fig. 4: The "My Page" of student who used the pseudonym Explosive Bean

\section{Discussion: Learning and Unlearning}

Embedding social and participatory media into my face-to-face classroom provided many opportunities for students to learn from each other and with these came a shift in the teacher-to-student relationship. Such a shift is discussed by Davis and Sumara (2012) and relates well to what Zhang (2012), in his discussion of new curriculum reform, calls the "blurring of the boundaries" (p. 90) between teaching and learning. This blurring of the boundaries can be seen in the learning that occurred in formal as well as informal online groups. Rhine and Bailey (2011) explain the natural tendency of students' attention to wander, over time, and the positive use of what they call "focused distractions." This occurs when it appears that students are being distracted, but the distraction is supporting the learning in ways that may not be obvious. In this study, informal groups could be considered to provide such distractions and these also have the potential to support different modes of learning. Zhang (2012), like Davidson and Goldberg, (2009), argues that modes of learning have changed and acknowledges the need for a continuous transformation of the roles of teacher and student where the teacher's authority becomes related to the concepts being studied and highlighted at the time. This could be seen in the examples discussed and is similar to Hamilton's (1990) concept of learning by seeking out knowledge.

The changes in teacher mind-set, experienced throughout this action research, harmonized with McWilliam's (2008) four challenges (listed earlier). Her first challenge: "less time giving instructions and more time spent being a usefully ignorant co-worker in the thick of the action" (p. 265) can be seen in the struggle with teacher time. In embedding social and participatory media into my curriculum, my teacher colleagues 
and critical friends called me an "innovator." However, considering McWilliam's second challenge, she may well call me a "risk-taker" and "an experimenter" as I spent less time being, what she called, a "custodial risk minimiser" (p. 265). Her third challenge: "less time being a forensic classroom auditor and more time spent being a designer, editor and assembler" (p. 265), can be seen through the changes in assessment approaches. The reflection data also indicates that I was spending less time being, what McWilliam might call, a counsellor and "best buddy" and spending more time being a collaborative critic and authentic evaluator (her fourth challenge). This could be seen as a shift from students seeking teacher feedback to a more collaborative combination of peer and teacher feedback. Students were not only being assessed on their project work, but also on the feedback they were giving to support their peers. This changed the dynamics of the classroom and, as the teacher, I had more time to provide constructive one-to-one support on how to improve their feedback.

During the initial four weeks (about 12 hours of contact time) of each of the three research phases, the teacher reflection data highlights a common statement from students: "but that's the teacher's job," indicating that a shift in their thinking was required before they could fully appreciate the move away from the traditional teacher approach. Davidson and Goldberg (2009) confirm that "a blurring between teaching and learning" (p. 16) is to be expected within dynamic learning environments. They assert that, with participatory learning, the play between technology, composer, and audience is no longer passive. Like Zhang (2012), Davidson and Goldberg (2009) explain that, with participatory learning, conventional modes of authority break down, and the examples for this study, as described earlier, support this concept and raise challenges for educators who are trained under a different set of premises.

In this study, challenges also included that of being seen to be doing and being different from the other 70 or so teachers at the school; I frequently struggled with the concept of being a good teacher as I worked with critical friends, presented at learning area meetings, curriculum meetings, and whole-school meetings of teaching staff. As the action research cycle progressed, the answers to questions concerning what a good class should look and sound like did not always meet with my colleagues' beliefs and this became a pedagogical struggle for me. I sought a wider critical friend base by presenting at conferences, locally and internationally. Developing this wider network of educators and academics provided me with further insight and encouragement. Reconceptualizing teaching and learning in Gough's (2012) complexivist terms, Doll's (1993) self-organization of curriculum, and Selwyn's (2008) state-of-the-actual, gave me further strength. In particular, I gained a great deal of confidence when the social network used in my third research phase received first place in an international 
award for innovative online learning in 2012.' Such support provided me with the confidence I needed to unlearn: to dispense with many of my traditional teaching behaviours. Davis and Sumara's (2012) discussion on "Learning About Learning" adds another perspective to McWilliam's (2008) notion of good teaching. They provide an interesting discussion around the concepts of the teacher being a learner. Davis and Sumara (2012) explain that this is one of a number of complexity-prompted shifts in structures in education, and they ask, "What is a teacher an expert in?" (p. 36). They provide the answer that "teachers should be learning experts." (p. 36). Davis and Sumara describe this as creating a sort of theoretical connoisseurship by developing an awareness of vital distinctions, varied implications, and hidden assumptions.

\section{Conclusion}

Through this action research study, social and participatory media was integrated into my face-to-face classes, and a shared dynamic, student-centred environment was built where students could interact across all of my classes. Students posted content, including project work, on blogs, group and discussion forums where online interactivity and user-generated content became an integral component of the classroom. Learning was supported by peers and by the teacher: hence, a shared, formal and informal student-centred environment was developed and was accessible anytime and anywhere. Such an approach can be integrated into other areas of education including university subjects and courses (Casey \& Wells, 2015).

This study found that there are new demands on teaching and learning within such a dynamic environment and these resulted in the need for me, as the teacher, to modify my pedagogical strategies and values which, in turn, required the unlearning of many aspects of my previous teacher professional life to take place. The study found that there was a need to construct a type of social pedagogy in order to take advantage of the unique qualities of social media. This supports Blatchford, Kutnick, Baines, and Galton's (2003) prediction that in the future, the distinction between teacher and student, or expert and novice, may well become blurred, especially as information becomes more widely, and instantly, available. Like Freire (cited in Zhang, 2012), this study found that the role of the teacher and students could be transformed. He states that:

The teacher is no longer just an instructor, and when communicating with students, teachers themselves can also benefit a lot. Students are taught by teachers and in turn, they also educate teachers. They grow up together through teamwork. 
In this process, the argument based on authority is no longer effective; in order to function, authority has to support freedom, not be against freedom. (p. 96)

When considering the title of this article, "Unlearning to Be the Teacher," Davis and Sumara's (2012) discussion on Learning About Learning, helped me to analyze my thoughts on teachers as learners. This study demonstrates that there are new complexities and tensions within teaching and learning. While the study supports Davis and Sumara's concept that teachers should be learning experts, I can't help but wonder that, as the practitioner-researcher, if I had been a learning expert then perhaps I would not have needed to "unlearn."

\section{Note}

1. See: http://www.iste.org/docs/pdfs/iste_awards_archives.pdf?sfvrsn=4

\section{References}

Armstrong, F., \& Moore, M. (2004). Action research: Developing inclusive practice and transforming cultures. In Felicity Armstrong \& Michele Moore (Eds.), Action research for inclusive education: Changing places, changing practice, changing minds (pp. 1-16). New York: RoutledgeFalmer.

Blatchford, P., Kutnick, P., Baines, E., \& Galton, M. (2003). "Towards a Social Pedagogy of Classroom Group Work." International Journal of Educational Research, 39: 153V172.

Casey, G. (2011). Knowledge-building: Designing for learning using social and participatory media. elearning Papers, 27, 1-7. Retrieved from: http://openeducationeuropa.eu/en/ node/111465

Casey, G. (2013). Building a student-centred learning framework using social software in the middle years classroom: An action research study. Journal of Information Technology Education: Research, 12, 159-189. Retrieved from: http://www.jite.org/docu ments/Vol12/JITEv12ResearchP159-189 Casey1186.pdf

Casey, G., \& Evans, T. (2011). Designing for learning: Online social networks as a classroom environment. The International Review of Research in Open and Distance Learning, 12(7), 1-26. Retrieved from: http://www.irrodl. org/index.php/irrodl/article/view/1011 and (published in Spanish): http://bdistancia. ecoesad.org.mx/contenido/numeros/nume ro7/presencia_01.html.

Casey, G., \& Wells, M. (2015). Remixing to design learning: Social media and peer-to-peer interaction. Journal of Learning Design, $8(1), 38-54$. 
Davidson, C., \& Goldberg, D. (2009). The future of learning institutions in a digital age. Massachusetts Institute of Technology.

Davis, B., \& Sumara, D. (2012). "Fitting Teacher Education in/to/for an Increasingly Complex World." Complicity: An International Journal of Complexity and Education, 9(1), 30-34.

Doll, W. (1993). A post-modern perspective on curriculum. New York: Teachers College Press.

Dunbar, R. (1996). Grooming, gossip and the evolution of language. Cambridge, MA: Harvard University Press.

González, N., Moll, L. C., \& Amanti, C. (2005). Funds of knowledge: Theorizing practices in households, communities, and classrooms. Mahwah, NJ: L. Erlbaum Associates.

Gough, N. (2012). "Complexity, Complexity Reduction, and 'Methodological Borrowing' in Educational Inquiry." Complicity: An International Journal of Complexity and Education, 9(1), 41-56.

Hamilton, D. (1990). Curriculum history. Geelong, Victoria: Deakin University.

Hendron, J. (2010). "Developing Info-Seeking Fluency." Learning \& Leading with Technology, 38(2), 31-32.
Ludvigsen, S. (2012). "What counts as knowledge: Learning to use categories in computer environments." Learning Media and Technology, 37(1), 40-52.

McWilliam, E. (2008). "Unlearning how to teacher." Innovations in Education and Teaching International, 45(3), 263-269.

Nuthall, G. (2007). The hidden lives of learners. Wellington, N.Z: New Zealand Council for Educational Research.

Rhine, S., \& Bailey, M. (2011). Enhancing in-class participation in a Web 2.0 world. In Charles Wankel (Ed.), Educating educators with social media (pp. 303-322). Bingley, UK: Emerald Group Pub.

Selwyn, N. (2008). "From state-of-the-art to state-of-the-actual? Introduction to a special issue." Technology, Pedagogy and Education, $17(2), 83-87$.

Zhang, G. (2012). "On the recursion between teaching and learning." Complicity: An International Journal of Complexity and Education, 9(1), 90-97.

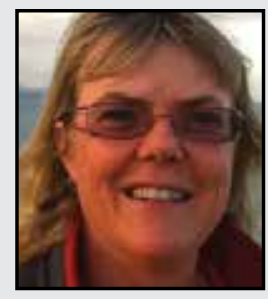

Gail Casey has been a high school teacher and K-12 eLearning Leader for many years and is currently a learning and assessment designer at Deakin University, Australia. Her area of expertise surrounds educational action research and self-study with the aim of building active and engaging learning opportunities for students. Gail has published in the areas of learning design and new media in education. In 2013, she received an outstanding paper award at the World Conference on Educational Media and Technology and a publication scholarship from Deakin University. In 2012, Gail was awarded, by ISTE, first place in the SIGOL Online Learning Awards. 